\title{
Escrita e Gênero na Pensadora Medieval Cristina de Pisano
}

\author{
Writing and Genre in the Medieval Thinker Cristina de \\ Pisano
}

\author{
Marcos Roberto Nunes Costa \\ (Universidade Federal de Pernambuco, Brasil) \\ Rafael Ferreira Costa \\ (Universidade Federal de Pelotas, Brasil)
}

Resumo: Não obstante já encontrarmos algumas mulheres que se destacaram como escritoras na Idade Média, algumas delas, inclusive, que trataram de temas relacionados a questão de gênero, como é o caso, por exemplo, de Hidelgard de Bingen (1098-1165), sendo por isso apontadas por alguns comentadores como precursoras do "feminismo", mas é Cristina de Pisano (1365-143?), provavelmente, a primeira escritora "feminista" no sentido moderno da palavra. Participou ativamente do famoso movimento crítico-literário no medievo que ficou conhecido pelo nome de Querelle des Femmes, em reação a literatura misógina da época, que teve como estupim o famoso poema Roman de la Rose, escrito por Jean de Meung, em 1280. Eis, portanto, o objetivo deste artigo: apresentar Cristina de Pisano como uma fecunda precursora do movimento feministas moderno, destacando-se, inclusive, em comparação com outras importantes pensadores de seu tempo, por ter feito da arte de escrever uma profissão, e de a colocar a serviço da "causa feminina".

Palavras-chave: Cristina de Pisano. Escritora. Educação. Feminismo.

\begin{abstract}
However, we have already met some women who stood out as writers in the Middle Ages, some of them even dealing with issues related to gender, as is the case, for example, of Hidelgard de Bingen (1098$1165)$, being by this is pointed out by some commentators as precursors of "feminism", but it is Cristina de Pisano (1365-143?), probably the first "feminist" writer in the modern sense of the word. He actively participated in the famous medieval literarycritical movement that became known by the name Querelle des Femmes, in reaction to the misogynist literature of the time, which had as its stupefy the famous poem Roman de la Rose, written by Jean de Meung, in 1280. Therefore, the objective of this article: to present Cristina de Pisano as a fruitful precursor of the modern feminist movement, even standing out in comparison with other important thinkers of her time, for having made the art of writing a profession, and for put at the service of the "female cause".
\end{abstract}

Keywords: Cristina de Pisano. Writer. Education. Feminism. 


\section{Introdução}

É corrente se afirmar que antes da chamada Modernidade não há registro de mulheres na construção do pensamento erudito. Que, se tomarmos, por exemplo, à Filosofia e à Teologia, que foram as duas áreas do conhecimento que mais produziram intelectuais durante a Idade Média, as quais muitas vezes se entrecruzaram, não encontraremos a presença das mulheres.

Realmente, se tomarmos por base alguns dados empíricos, como, por exemplo, os Manuais ou Compêndios de Filosofia/Teologia (comumente chamados de História da Filosofia/Teologia), pelo menos na sua grande maioria, não aparece nenhuma mulher na lista dos chamados Filósofos/Teólogos ${ }^{1}$.

Entretanto, apesar de todas as evidências, se vasculharmos a construção do pensamento ocidental, veremos que as mulheres sempre estiveram presentes, contribuindo indireta ou diretamente, desta história. E é possível até identificamos a presença de algumas delas já nos tempos remotos, na Filosofia Clássica Antiga, por exemplo, passando pela Patrística (ou Alta Idade Média), pela Escolástica (ou Baixa Idade Média) até alcançarmos o Renascimento.

Mas foi no alvorecer da Baixa Idade Média, em pleno período de efervescência intelectual, em que apareceu grandes personagens do pensamento ocidental, que encontramos as primeiras pensadoras, responsáveis por um sistema autônomo, destacando-se como fecundas escritoras, donas de obras tão profundas e importantes quanto as dos pensadores de seu tempo, com os quais muitas vezes dialogaram em pé de igualdade.

Dentro desse maravilhoso universo feminino do conhecimento, destacamos, na Escolástica, a figura de Cristina de Pisano (1365-143?), a primeira mulher que fez da arte de

\footnotetext{
${ }^{1}$ No que se refere à Idade Média, até onde conhecemos, o único Manual de Filosofia Medieval que traz ou classifica mulheres em seu elenco é o seguinte: SARANYANA, Josep-Ignasi. História de la filosofia medieval. 3. ed. Pamplona: EUNSA, 1999.

6 • Ágora Filosófica, Recife, v. 21, n. 2, p. 05-27, mai./ago., 2021
} 
escrever uma profissão, e de a colocar a serviço da "causa feminina", sendo, provavelmente, a primeira escritora "feminista" no sentido moderno da palavra. Foi líder do famoso movimento literário no medievo que ficou conhecido pelo nome de Querelle des Femmes, em reaçao a literatura misógina da época, que teve como estupim o famoso poema Roman de la Rose (Romance da Rosa), escrito por Jean de Meung, em 1280.

\section{Uma mulher que fez da arte de escrever uma profissão}

Cristina de Pisano, ou Christine de Pizan, em Francês, língua adotada na qual escreveu suas obras, filha de Tommaso di Benvenuto Pisano, médico, astrólogo e professor da Universidade de Bolonha, nasceu em Veneza - Itália, em 11 de setembro de 1365 .

Em 1368, seu pai foi nomeado secretário de Carlos V, rei da França. Assim,

quando sua filha tinha três anos, a família se transferiu paraParis, e desde então a pequena Cristina começou a ter contato com a Corte, com a família real e com a burocracia de palácio, tendo acesso a grande biblioteca do mesmo e a produção de livros que se realizavam para o monarca. Ali conheceu não só os clássicos, senão que as primeiras traduções ao francês de alguns autores que posteriormente exerceriam grande influência em suas obras, como foi o caso de Boccaccio. Assim, pois, a infância e adolescência de Christine de Pizan transcorreram em meio a este ambiente erudito, tendo como respaldo a influência e ajuda de seu pai, que a colocou em contato com os círculos intelectuais da época, ainda que sem o consentimento de sua mãe (ARAUZ MACEDO, 2005, p. 215)².

Confirmem/completam essas informações Ana Wuensch, que diz: "De seu avô materno recebeu as primeiras lições científicas do corpo humano, aprendendo a Ágora Filosófica, Recife, v. 21, n. 2, p. 05-27, mai./ago., $2021 \cdot 7$ 
Em 1380, aos 15 anos de idade, casou-se com um francês dez anos mais velho do que ela, denominado Etienne du Castel, que, em 1386, um ano após o casamento, assumiu a função de secretário da chancelaria do Rei Carlos V.

Sete anos depois, Cristina de Pisano perde o pai, e, três anos depois, em 1390, morre seu marido, fatos que a deixaram, juntamente com os demais familiares, numa delicada situação financeira. É então que Cristina de Pisano decide dedicar-se às letras, numa tentativa de sustentar a si, a mãe, os dois irmãos, os três filhos e uma sobrinha que tinha a seu encargo, sendo, por muitos comentadores, a primeira mulher a viver ou ganhar a vida como escritora, ou a fazer da arte de escrever uma profissão. Nesse sentido, Vilma Lima diz que "Pizan inovou porque fugiu aos padrões femininos vigentes em seu tempo e, mais ainda, sustentou-se de seu trabalho como escritora, algo incomum para uma mulher medieval" (2011, p. 18). E, mais adiante, completa: "[...] para manter-se e a sua família continuou escrevendo, direcionando-se por literaturas que tratavam da arte da guerra, da administração real e, sobretudo, da defesa da mulher" (Ibid.). Mais do que isto, para Luciana Calado Deplagne, Cristina de Pisano não foi só a primeira mulher a sobreviver da arte de escrever, mas, o mais curioso, a "viver de uma escrita 'feminista' em defesa da mulher, como uma doce voz na amarga misoginia da época" (2006, p. 25) ${ }^{3}$.

admirar a sua natureza e beleza, e afastando-se dos preconceitos da medicina tradicional da época; de seu pai, as lições de astronomia e astrologia então se complementavam. Foi ele quem providenciou que sua filha aprendesse letras (italiano, francês e latim), bem como poesia (história) e retórica [...]. Eustache Descamps, poeta famoso em sua época, entre outros, e amigo de seu pai, orientou-a no estudo das artes liberais e da teologia" (2012, p. 5). Igualmente diz Vilma Lima: "Em seu pai, Christine encontrou incentivo para estudar e deleitar-se nos livros e manuscritos da biblioteca real, à qual ela tinha livre acesso" (2011, p. 11). Ao contrário de sua mãe, segundo Daniele Souza, "que embora fosse filha de um homem instruído, o anatomista Mondino de Luzzi, se opunha duramente à instrução da filha em matérias que não se referissem às tarefas domésticas. Ela refletiu o pensamento da grande maioria das pessoas de sua época, de que os estudos corrompiam as mulheres, sendo então impróprio esse tipo de educação 'masculina' a uma jovem" (SOUZA, 2008, p. 14). Cf. também, SOUZA, 2013, p. 21 e FONSECA, 2011, p. 555.

${ }^{3}$ Cf. também, LEITE, 2008, p. 12.

8 • Ágora Filosófica, Recife, v. 21, n. 2, p. 05-27, mai./ago., 2021 
E assim,

em pouco tempo, Christine, detentora de erudição singular, produziu obras bastante diversificadas como poemas, tratados de educação, morais e políticos, entre outros, mas todos com destaque à temática frequente do universo feminino e à exposição pioneira da noção de que as diferenças entre homens e mulheres não se encontravam em questões biológicas, ínsitas à própria natureza dos gêneros, mas em construções de origem religiosa, cultural e social (NERI, 2013, p. 71).

Começou a escrever, em 1394, com uma obra que seria intitulada Livre des Cent Ballades (Livro das Cem Baladas), sob a encomenda das esposas dos príncipes ${ }^{4}$. A obra teve boa aceitação na época. Nela, em forte tom de lirismo melancólico, a autora se autorretrata ou externa seus sentimentos em relação aos últimos e difíceis tempos que estava vivendo, a ponto de desejar a morte, como vemos, por exemplo, em algumas estrofes das baladas V, VIII e IX:

Maldita vida que dura tanto,

Pois, nada mais me apetece,

Apenas morrer, continuar vivendo não tem mais sentido

Depois que morreu aquele que me deixava em vida

(Balada V, 5-8).

Para qualquer lado que me vire,

4 Por ter-se dedicado à vida literária para sobreviver, Cristina de Pisano, além de escritora, foi também copista e artista plástica, conforme relata SOUZA, 2013, p. 28: “Cristina de Pizan foi copista e dedicou-se a escrever influenciada pelas necessidades que vieram com a viuvez, tornando-se uma escritora profícua, que também fazia as iluminuras de suas obras, reconhecida ainda em vida graças ao apoio da corte francesa devido às suas relações pessoais". E assim, sob encomenda de princesas e príncipes, copiou e escreveu diversas obras, dentre as quais biografias de famílias reais.

Ágora Filosófica, Recife, v. 21, n. 2, p. 05-27, mai./ago., $2021 \cdot 9$ 
Não vejo nada que me pareça importante,

Eis as razões de minhas lamentações

(Balada VIII, 12-14).

E tu, Morte, eu te peço, inscreve-me em teu livro

E faze com que eu veja em breve tal mensagem

Que meus males queixosos sejam por ti aliviados

(Balada IX, 26-28) (apud DEPLAGNE, 2006, p. 27).

\section{Uma escritora comprometida com a "causa feminina"}

Mas, o que lhe garantiu o estatuto de escritora ou a notoriedade alcançada foram os escritos em resposta ao famoso poema Roman de la Rose (Romance da Rosa) ${ }^{5}$, um dos livros mais populares em toda Europa no século XIII ${ }^{6}$, de cunho misógino, principalmente na sua segunda parte, onde representa as mulheres como nada mais que sedutoras, numa mordaz sátira às convenções do amor cortês ${ }^{7}$.

\footnotetext{
${ }^{5}$ As reações/polêmicas em torno do Roman de la rose (Romance da rosa), incluindo aí as obras de Cristina de Pisano, receberam, mais tarde, o nome de Querelle des Femmes. Segundo Ana Wuensch, "por meio de suas correspondências, ela [Christine] reúne aliados para sua causa, tanto da nobreza - como o duque de Orléans, e a própria rainha da França, Isabel da Baviera - quanto da universidade, como o teólogo Jean Gerson, que escreve, em 1402, um tratado contra a versão do Roman de Jean de Meung, em favor de Christine de Pizan" (2012, p. 7). Já do lado contrário, temos "alguns intelectuais e personalidades ligadas ao rei, como Pierre Col e Jean de Montreuil, que, contrários às opiniões da escritora, além de criticarem sua obra, pedem, em duas Epístolas, que ela retire as críticas que fez sobre o Roman de la Rose" (DEPLAGNE, 2020). Cf. também, SOUZA, 2013, p. 31.

${ }^{6}$ Segundo Joseph-Ignasi Saranyana, "sem competidor algum, foi a obra mais popular e influente no Baixo Medievo" (2007, nota 8, p. 117).

7 Segundo Vilma Lima, o Roman de la Rose foi escrito por dois autores: "a primeira parte da obra foi escrita por Guilherme de Lorris, em 1230; nela a mulher era enaltecida e o amor se expressava embalado em poemas românticos; a segunda parte foi escrita por Jean de Meung, em 1280. Esse autor impôs um caráter depreciativo na obra no que diz respeito à mulher, ridicularizando-a, diminuindo-a na sua condição de gente" (2011, p. 12). Há uma versão brasileira da primeira parte desta obra, traduzida por Sonia Regina Peixoto, Eliane Ventorim e Ricardo da Costa, disponível na página: http://www.academia.edu/2997637/O_Romance_da_Rosa.

10 • Ágora Filosófica, Recife, v. 21, n. 2, p. 05-27, mai./ago., 2021
} 
Em 1401, Cristina de Pisano inicia suas obras antimisóginas, criticando o referido poema, que, segundo ela, era infundado e serviam apenas para denegrir a função natural e própria da sexualidade feminina. No poema Épître au Dieu d'Amour (Epístola ao Deus de Amor), por exemplo, ela diz:

Que não me acusem de desatino, de arrogância ou presunção, de ousar, eu, mulher, opor-me e replicar um autor tão sutil, nem de reduzir o elogio devido à sua obra, quando ele, único homem, ousou difamar e censurar sem exceção todo o sexo feminino (apud RÉGNIER-BOHLER, 1990, v. 2, p. 530).

Assim, por criticar a misoginia presente no meio literário da época e defender o papel das mulheres na sociedade, Cristiana de Pisano é considerada, ainda hoje, precursora do feminismo moderno.

Mas, as duas obras antimisóginas de Cristina de Pisano de maior repercusão foram o Livre de la cité des dames (Livro da cidade das damas) e o Livre des trois vertus (Livro das três virtudes) ${ }^{8}$.

A primeira delas - Livre de la cité des dames (Livro da cidade das damas) -, escrita em 1405, em 03 livros, dividida em 138 capítulos, nasceu após a leitura de Lamentations (Lamentações), da autoria de Matheolus, uma obra do século XII traduzida para o francês em 1370 por Jean Le Fèvre, que provocou grandes inquietações na leitora, conforme ela mesma

\footnotetext{
${ }^{8} \mathrm{Na}$ Introdução de sua tradução espanhola da obra A Cidade das Damas, Marie-Jose Lemarchand que "durante mais de trinta anos - de 1398 a 1429 - a obra de Cristina de Pizán esteve centrada na mulher. A primeira obra em que a escritora discute acerca da condição feminina é a Epístola ao Deus Amor; logo a seguem as Cartas da Querela do Romance da Rose (1398-1402), A Cidade das Damas, obra chave, O Tesouro da Cidade das Damas, a qual já aludimos, para terminar com o canto à mulher que reúne todas as virtudes femininas que triunfam na Cidade das Damas: guerreira como Minerva, fundadora de reinos como Dido, profetisa como as sibilas o Casandra: é a Canção em honra a Joana D'Arc (1429), escrita por Cristina no umbral da morte quando a pobre Pucelle já estava encarcerada no donjeon normando" (In: CHRISTINE de Pizan, 2000, p.
} 24).

Ágora Filosófica, Recife, v. 21, n. 2, p. 05-27, mai./ago., 2021 • 11 
relata no início de referida obra:

Um dia, estava eu, como de hábito, e com a mesma disciplina que rege o curso de minha vida, recolhida em meu gabinete de leitura, cercada de vários volumes, tratando dos mais diversos assuntos. Com a mente cansada por ter passado um bom tempo estudando sentenças complexas de tantos autores, levantei a vista do texto, decidindo deixar, por um momento, assuntos mais sutis para deleitar-me com a leitura de alguma poesia. E, com esse intuito, procurando à minha volta algum livreto, caiu entre minhas mãos um certo opúsculo que não me pertencia, mas que alguém havia deixado ali, com outros volumes, por empréstimo. Abri-o, então, e observei no título que se tratava de Monteolo $^{9}$ [...]. Pus-me a lê-lo. Avancei um pouco a leitura. Mas, o assunto, parecendo-me pouco agradável -, aliás, para qualquer um que não se deleita com calúnias -, e sem contribuir em nada à edificação moral nem à virtude, considerando ainda a distorção da linguagem e dos temas por ele tratados, folheei-o aqui, ali, li o final, e, em seguida, abandonei-o para voltar a outros estudos mais sérios e de maior utilidade. Porém, a leitura daquele livro, apesar de não ter nenhuma autoridade, suscitou em mim uma reflexão que me

${ }^{9}$ Outras obras bastante citadas pela literatura misógina da época, bem como por Cristina de Pisano, foram A Arte de Amar, de Ovídio, e o De Secretis Mulierum (Sobre os Segredos das Mulheres), "um aberrante tratado de ginecologia de grande circulação no século XIII, que denega, seguindo a tradição de Aristóteles e de Santo Isidoro de Sevilha, os efeitos corruptos da menstruação" (FONSECA, [s.d.]), atribuído ao PseudoAlberto Magno. Esta obra, segundo Verônica Roldós, tema "mais de 50 edições impressas no século XV, e ao redor de mais de 70, no século XVI". Em 2011 saiu uma versão espanhola dessa obra, publica em uma editora de Portugal: ALBERTO Magno, Pseudo. El De Secretis Mulierum, atribuído a Alberto Magno: estúdio, ediccíon crítica y traducción de José Pablo Barragán Nieto. Porto: Faculdade de Letras/Gabinete de Filosofia Medieval, 2011. 587 p.

12 • Ágora Filosófica, Recife, v. 21, n. 2, p. 05-27, mai./ago., 2021 
atordoou profundamente [...] (CHRISTINE de Pizan, I, 1, 2012, p. 57-58)

\section{E continua:}

Perguntava-me quais poderiam ser as causas e motivos que levavam tantos homens, clérigos e outros, a maldizer as mulheres e a condenar suas condutas em palavras, tratados, escritos [...]. Filósofos, poetas e moralistas [...] todos parecem falar com a mesma só voz para chegar à conclusão de que a mulher é profundamente má e inclinada ao vício (Ibid., p. 58).

Nas palavras de Pedro Barbosa, como reação à referida obra, ou

para provar que as mulheres não eram seres inferiores, esta letrada, um dos espíritos mais cultos do seu tempo, vai compilar as vidas de um conjunto de outras mulheres que se tinham notabilizado, desde a bíblica Rute até Branca de Castela, mãe de S. Luís, passando por Penélope, mulher de Ulisses, e Agripina a Maior (2001, p. 182).

Para isso, tomando como referência a obra $A$ Cidade de Deus, de Santo Agostinho ${ }^{10}$, ainda que para contextar ${ }^{11}$, Cristina

\footnotetext{
${ }^{10}$ Lucimara Leite, ao falar da estrutura da obra, diz que "a ideia e o título usados por Christine revelam uma cidade alegórica, provavelmente inspirada em $A$ Cidade de Deus, de Santo Agostinho. Já a divisão em três partes foi influenciada por Petrarca e outros" (2008, p. 101).

${ }^{11} \mathrm{~A}$ esse respeito diz Pedro Fonseca: "E nesse sentido dialético de construir desconstruindo que Christine constrói o seu polêmico Livro da cidade das damas (Le livre de la cite des dames), talvez como uma réplica a Cidade de Deus que Santo Agostinho havia escrito em contraposição a cidade deste mundo. Portanto, mais do que a ostensiva Cidade de Santo Agostinho, a Cidade de Christine e uma construção defensiva: e construída sobre a reputação de mulheres, histórica e lendariamente, conspícuas em todo o campo de empreendimento ou moralidade; uma verdadeiramente nova fortaleza para oferecer proteção ao sexo indefeso contra correntes sucessivas de discriminação e ultraje misóginos" (2011, p. 556). Mas Ágora Filosófica, Recife, v. 21, n. 2, p. 05-27, mai./ago., $2021 \cdot 13$
} 
de Pisano irá contruir uma cidade utópica constituída por mulheres, tendo como exemplos ${ }^{12}$ mulheres virtuosas de todos os tempos, que viveram em mundos feitos por e/ou para homens $^{13}$, as quais são reinterpretadas por ela a partir e/ou em

Christine escolhe diretamente como seu principal perturbador misógino o volumoso livro As Lamentações de Mateolo (c.1371-1372), provavelmente na tradução de Le Fevre do poema autobiográfico em latim intitulado Livro das Lamentações de Mateolo (Liber Lamentationum Matheoli) (c. 1295), de Mathieu de Bologne" (Ibid., p. 556-557). Além, disso, completa, o referido comentador, "pode-se deduzir, em confronto com outras passagens da Cidade das Damas, que a releitura de Christine e de raízes antigas. Aristóteles, no seu livro Sobre a Geração dos Animais (De Generatione Animalium) (século IV a. C.) e Galeno, no seu livro Sobre a Utilidade das Partes do Corpo (De usu Partium) (do século II), expondo uma anatomia e fisiologia deformadas nas mulheres, inquiriam se elas contribuíam com alguma coisa a mais para a geração além servirem de simples lugar ou espécie de incubadora para tal geração (ARISTOTLE, 1963, p. 91 93, 97, 101-103, 173-175, 185, 459-461; GALLEN, 1968, p. 630-632)" (Ibid., p. 557). Além é claro, "o virulento libelo misógino intitulado Sobre os Segredos das Mulheres (De Secretis Mulierum), um aberrante tratado ginecológico de grande circulação no século XIII, que denega como corrompedora a menstruacão, na esteira da mais fiel tradição misógina exposta por Santo Isidoro de Sevilha nas suas Etimologias (Etymologiae)" (lbid., p. 558).

${ }^{12}$ Segundo Lucimara Leite, para a construção desta obra Cristina de Pisano usou como modelo o Exemplum, que era um estilo literário muito comum desde os gregos e que ganhou força na Tradição cristã, que fazia das vidas dos santos um instrumento catequético-pedagógico de educação do povo" (2008, p. 08). Ou seja, “o exemplum é uma série de histórias (compilatio), geralmente curtas, que servem para induzir a pessoa que as escuta ou lê a seguir o modelo apresentado" (Ibid., p. 22). "Em La cité des dames, Christine faz uso do exemplum, pois, nessa obra, ela elenca uma série de mais de cem exemplos, pequenas histórias de mulheres com vida digna de imitar" (Ibid., p. 23). Partilha da mesma ideia Christiane Neri, 2013, p. 69. Christiane KlapischZuber, por sua vez, acrescenta que "o modelo de muitos dos retratos femininos da sua Cidade das Damas tinha-o Cristina encontrado em Bocácio, que por sua vez o tinha plagiado dos autores antigos e das lendas familiares, de forma a erigir o corpus das suas Mulheres llustres, espelhos das virtudes desejáveis e dos excessos do caráter feminino" (1990, v. 2, p. 10). Sobre o que pondera Mercedes Floréz: “Não duvidamos de que Boccaccio seja o direto inspirador de La ciudad de las damas de Christine de Pizan. Existem códigos comuns entre ambos os autores, ainda que esteja claro que a distância entre ambos é abismal: a nível ideológico, Cristine se coloca na linha de valorização das capacidades morais e intelectuais das mulheres, eliminando as partes misóginas ou demasiado sensuais dos textos de Boccaccio. Ademais, como assinala Ana Vargas, Cristine coloca as mulheres na ordem social, extraindo-as do imobilismo da ordem natural em que as coloca o autor do Decameron" (2012, p. 17-18).

${ }^{13}$ Segundo Marion Guarinos, "Christine usava uma pedagogia de exemplos para colocar em cena mulheres que por si próprias chegaram ao conhecimento por meio de sua coragem, de sua força e de suas virtudes. Dessa forma, as mulheres tomavam consciência do que elas também podiam fazer e não se deixavam influenciar pela imagem negativa que lhes era apresentada pelos homens" (GUARINOS apud LEITE,

14 • Ágora Filosófica, Recife, v. 21, n. 2, p. 05-27, mai./ago., 2021 
proveito das mulheres, ou seja,

recorrendo às origens, Christine redefine alguns mitos, e transforma a sua obra em uma verdadeira enciclopédia de mitos femininos, criando uma versão diferente para alguns mitos construtores da imagem deformadora do feminino. Assim, mitos históricos, mitos cristãos - em particular, o mito da origem, o mito do pecado original - e figuras míticas, legendárias da mitologia clássica e da Bíblia, encontraram nova roupagem nas versões narradas por Christine em La cité des dames (DEPLAGNE, 2006, p. 83).

Ou seja, acentua Marion Guarinos,

Christine usava uma pedagogia de exemplos para colocar em cena mulheres que por si próprias chegaram ao conhecimento por meio de sua coragem, de sua força e de suas virtudes. Dessa forma, as mulheres tomavam consciência do que elas também podiam fazer e não se deixavam influenciar pela imagem negativa que Ihes era apresentada pelos homens (GUARINOS apud LEITE, 2008, p. 69).

Mais do que isto, embora a obra de Cristina de Pisano esteja fundamentada na sua maioria em dados da empiria, ou seja, histórias concretas de mulheres virtuosas que viveram em determinado tempo histórico, em muitos pontos encontramos uma verdadeira fundamentação filosófico-ontológica, quando trata, por exemplo, da natureza humana, em que reinterpreta a criação (bíblica) da mulher a partir do homem de forma a estabelecer uma relação de igualdade entre ambos os sexos. No caso aqui citado, por exemplo, diz que, por ter sido criada da costela do homem, a mulher traz na sua essência a mesma 
centelha da luz divina que o homem, o qual, por sua vez, foi feito à imagem e semelhança de Deus, daí a mulher ser tão inteligente quanto o homem.

E dentre os pontos que tornam Cristina de Pisano diferente das fontes de que bebeu, podemos citar sua visão positiva ou otimista da natureza humana, da história e da ciência, exposta claramente em sua obra:

É verdade que alguns autores, especialmente o poeta Bocácio, de onde essas histórias foram contadas, diziam que o mundo era melhor quando se vivia de glandes e frutas selvagens, e vestia-se com peles de animais, ignorando todas as técnicas que nos permitem viver mais confortavelmente [...]. E se a humanidade faz mal uso dos bens que Deus the prometeu e the acordou para conveniência e benefício dos homens e das mulheres, transformando em maldade $\mathrm{e}$ perversidade, não é porque a coisa em si não seja vantajosa e excelente, se usada de maneira lícita (CHRISTINE de Pizan, I, 39, 2012, p. 148).

E acreditava que nesse processo de construção de um mundo melhor, pela via da razão, não só os homens, mas também as mulheres estavam aptas a contribuir:

Deus, que não fez nada sem justificativa, quis mostrar aos homens que não subestimou o sexo feminino em relação ao deles. Diga-se a propósito, Ele achou por bem conceder às mulheres uma inteligência tão brilhante, que elas podem não somente aprender e assimilar ciências, mas também inventar novas ciências de maior utilidade e benefício à humanidade, que dificilmente poderíamos encontrar mais necessárias (Ibid. I, 37, 2012, p. 143). 
Por isso faz da educação o principal meio de ascensão da mulher na sociedade, que ela acredita ser tão capaz quanto o homem, afinal é um animal racional tanto quanto o homem. Daí, em determinada ocasião diz: "Se fosse um hábito mandar as meninas à escola e ensinarIhes as ciências, como o fazem com os meninos, elas aprenderiam as sutilezas de todas as artes e de todas as ciências tão perfeitamente quanto eles" (Ibid., I, 26, 2012, p.126) ${ }^{14}$.

E assim Cristina de Pisano transforma suas obras, ou se apresenta como um instrumento pedagógico a serviço da humanidade, em especial da mulher, semelhante ao papel desempenhado pelo filósofo no mito da caverna de Platão, que volta à caverna para libertar os homens da alienação em que viviam.

Na cidadela de Cristina de Pisano as mulheres estariam protegidas de toda sorte de dissabores, infortúnios e maledicências próprias das cidades utópicas projetadas pelos homens.

Para tal, transforma alegoricamente os exemplos de mulheres por ela escolhidas em elementos constitutivos de uma cidade segura, virtuosa, ética, sábia, etc, em síntese, uma cidade perfeita, onde, diz Luciana Deplagne na Apresentaçao de sua tradução da obra $A$ Cidade das Dmas, as mulheres "possam ser reconhecidas como seres humanos e em igualdade com os homens, nas várias instâncias da vida cotidiana" (In: CHRISTINE de Pizan, 2012, p. 23). Assim, por exemplo, no que se refere à constituição física, para os alicerces da cidade é colocada como primeira pedra de fundação ou de base, por sua coragem, a guerreira Semíramis. Em seguida, como pedras de elevação dos altos muros, são escolhidas mulheres sábias, como Carmente, dentre outras. As pedras das torres com as quais são erguidas

\footnotetext{
${ }^{14} \mathrm{~A}$ esse respeito comenta Lucimara Leite: “Em Cité des dames, apresenta exemplos de mulheres sábias, mulheres que se destacaram porque tiveram a chance de estudar, mulheres que exerceram importantes papéis na política [...]" (2011, p. 171).

Ágora Filosófica, Recife, v. 21, n. 2, p. 05-27, mai./ago., $2021 \cdot 17$
} 
as torres e os palácios são escolhidas entre as profetisas da Bíblia e as sibilas. E assim por diante.

Para as funções ou instituições constitutivas de uma cidade perfeita são escolhidas, igualmente, mulheres virtuosas. Assim, as atividades da vida prática são representadas nas figuras de Vénturie, Clotilde, Minerva, Ceres, Ísis, dentre outras. Para representantes das atividades políticas e de poder são extraídas, dentre as rainhas, mulheres que foram capazes de administrar suas casas e/ou propriedades quando da ausência dos maridos, e aí aparecem Nicole, Gaia, Cecília, as rainhas Jeane e Blanche, e outras. Quando trata das atividades do conhecimento científico, cita Probe, Mântoa, Medeia, Hortência, e a própria Cristina de Pisano. Finalmente, para não nos alongarmos muito nos exemplos, ao tratar das qualidades ético-morais próprias dos habitantes da cidade, como fidelidade, honestidade, caridade, bondade, castidade, etc., traz figuras de mulheres como Júlia, Xantipa, Paulina, Sarah, etc.

Todas elas são guiadas por três virtudes capitais - Razão, Retidão e Justiça -, três figuras metafóricas femininas que, juntamente com Cristina de Pisano, são as protagonistas da obra. Essas três virtudes aparecem na obra como independentes, mas, ao mesmo tempo, unidas e inseparáveis entre si, analogamente às três pessoas da Santíssima Trindade, que formam a perfeição: Deus. Mas, como Cristina de Pisano precisava representar simbolicamente o último estágio, o da perfeição, numa figura feminina, entra aí a figura da Virgem Maria, responsável pelo comando das três referidas virtudes, por ser a maior, a mais sábia, a mais virtuosa, etc. de todas as mulheres ${ }^{15}$.

A segunda obra marcadamente antimisógina de Cristina de Pisano - Livre des Trois Vertus (Livro das Três Virtudes ou 0 Espelho de (ristina) ${ }^{16}$, escrita em 1406, debate questões ético-

\footnotetext{
${ }^{15}$ Alguns comentadores dizem que esta foi a forma encontrada por Cristina de Pisano para representar a Trindade - Deus, de uma forma feminina, ou, como diz Daniele de Souza, de "revelar o lado feminino de Deus" (2008, p. 27).

${ }^{16}$ Acerca desta segunda forma de tradução do título diz Mônica Karawejczyk: "O Espelho 18 - Ágora Filosófica, Recife, v. 21, n. 2, p. 05-27, mai./ago., 2021
} 
morais a serem vividas em sociedade, principalmente pela mulheres, de tal forma que muitos a consideram como uma continuidade da obra anterior. Inclusive ela é escrita em torno das mesmas três virtuosas senhoras: Razão, Retidão e Justiça, as quais,

personificam as principais virtudes que as mulheres deveriam seguir, oferecendo seus conselhos para que, visando o afastamento da mulher das tentações que os pecados representam, possam alcançar o bem viver em sociedade e o paraíso final no final de suas vidas eternas (KARAWEJCZYK, 2007, p. 159).

Entretanto, enquanto o Livre de la Cité des Dames (Livro da Cidade das Damas) foi construído segundo o modelo do exemplum, o Livre des Trois Vertus (Livro das Três Virtudes) é inspirado no speculum ou miroir (espelho), outro estilo literário muito próximo do exemplum, também muito usado desde os gregos e fortemente difundido na Tradição cristã, que "apresenta modelos de comportamento que devem ser refletidos e copiados, desde os atos mais simples do cotidiano até aqueles que estavam voltados a uma formação mais ampla e geral" (LEITE, 2008, p. 22), transformando-se numa espécie de Manual de Moral. E, dentre as obras que influenciariam o Livre des Trois Vertus (Livro das Três Virtudes) de Cristiana de Pisano, estaria o chamado Speculum Principi (Espelho de Príncipe), que teve várias versões, escritas por vários pensadores antigos e medievais, e com títulos diversos ${ }^{17}$.

de Cristina é uma edição fac-similada editada pela Biblioteca Nacional de Lisboa no ano de 1987. Esta obra é a versão portuguesa do manuscrito francês de 1405, intitulado Le Livre des trois vertus, cujo original se encontra na Biblioteca Nacional da França" (2007, p. 149).

${ }^{17}$ Dentre os diversos Speculum principi de cunho político-pedagógico, que certamente chegaram ao conhecimento de Cristina de Pisano, podemos citar: o Policratus (1159), 
As várias versões do Speculum são simplesmente escritos político-pedagógicos dirigidos a homens que ocupavam o governo ou se achavam em situação de sucessão ${ }^{18}$.

Daí a comentadora Lucimara Leite diz que

o ponto comum entre essas obras é a construção de um modelo de governante que segue atributos tais como: submeter-se aos desígnios de Deus, pois dele provém o seu poder; defender a Igreja e os seus membros; procurar pautar sua vida pelas virtudes (justiça, paciência, generosidade e temperança); servir de exemplo a ser seguido por seus súditos; aconselhar-se com homens sábios, honrados e honestos; evitar os bajuladores, assim como a avareza e a luxúria (2008, p. 29).

E são justamente esses pontos que aparecem principalmente nos livros I e II do Livre des Trois Vertus (Livro das Três Virtudes) de Cristina de Pisano, no qual ela instrui as mulheres sobre como exercer o governo da cidade quando da ausência de seus maridos.

Além do Espelho de Príncipe, de caráter éticopolítico-pedagógico, existiram outros tipos de Espelhos que influenciaram a obra de Cristina de Pisano, como os de cunho ético-moral, a exemplo do Miroir des Vierges ${ }^{19}$. Esta obra, de autoria anônima, que apareceu na França no

de Jean de Salisbury; o Eruditio filiorum nobilium (1246), de Vincent de Beauvais; o Eruditio regum et principum (1259), de Gilbert de Tournai; o De regimine principum, de Tomás de Aquino e o De regimine principum (1287), de Egídio Romano.

${ }^{18}$ Por isso diz M. R. C. Muniz que os Speculum eram "manuais de formação não só de reis e príncipes, mas também de senhoras de variada estrutura social, bem como de religiosos, que se serviam de seu prolixo conteúdo ético-político" (2003, p. 24).

${ }^{19}$ Além dessa obra, outros exemplos de Speculi de cunho ético-moral-religioso que influenciaram Cristina de Pisano, podemos citar: Miroir de l'Église (1140), de Honorius Augustodunensis; Le Miroir des Simples Âmes (O espelho das Almas Simples), de Marguerite Porete; Speculum Dominarum (Espelho das Donas de Casa) de Durand de Champagne, e o Miroir des Dames (Espelho das Mulheres), de Watriquet de Couvin.

20 • Ágora Filosófica, Recife, v. 21, n. 2, p. 05-27, mai./ago., 2021 
século XII, tem, nas partes quarta e sétima, grande afinidade com o Livre des Trois Vertus (Livro das Três Virtudes) de Cristina de Pisano. Baseada na personagem bíblica Judith, trata do fundamento das virtudes e dos vícios, do orgulho e da humildade, aconselhando as mulheres sobre o modo de se comportarem numa sociedade na qual o papel da mulher é determinado pelas diferenças de classes.

Desconhece-se a data exata da morte de Cristina de Pisano, mas tudo indica que faleceu em torno de 1430, no mosteiro de Poissy - França, onde viveu os últimos anos de sua vida, embora sem nunca ter sido freira.

\section{Considerações finais}

Por tudo isso, concluimos que Cristina de Pisano (1365-143?) foi veradeiramente uma precusora do "feminismo" no sentido moderno da palavra, pois, não obstante termos outras pensadoras no medievo tão fecundas quanto ela, ou até mais, mas, nenhuma outra tocou das questões de gênero de maneira tão moderna como ela.

Hidelgard de Bingen, por exemplo, embora tenha contrariado a ortodoxia católica em pontos importantes, como, por exemplo, ao defender que a semelhança do homem com Deus não é apenas pela alma, inclui aí também o corpo e, é claro, o corpo feminino, conforme acentua J.-I. Saranyana:

Convêm assinalar que para Hildegarda de Bingen, a mulher não é só imagem de Deus enquanto alma, senão também enquanto corpo, quer dizer, pela carne [...] tanto do varão como da mulher (1999, p. 155).

Ágora Filosófica, Recife, v. 21, n. 2, p. 05-27, mai./ago., 2021 • 21 
Mas, apesar dessa valorização da mulher, deixando transparecer, nas entrelinhas, certo feminismo em seu pensamento, o que levou muitos comentadores atuais a classificá-la como uma "teóloga feminista", não podemos dizer que de fato Hildegarda tivesse tal pretensão, muito menos que buscasse uma emancipação da mulher, haja vista que, em nenhum momento esta questiona o papel ou a situação social da mulher na Igreja e na sociedade. Daí ter dito Maria Carmen Poll que, "embora Hildegarda tenha sido, de fato, em muitos aspectos uma mulher à frente do seu tempo, ela nunca reivindicou para si ou para o papel das mulheres de sua época qualquer mudança" (2010, p. 28-29), pelo contrário, a esse respeito, em muitos pontos defende posições conservadoras ou tradicionais a esse respeito.

Um dos pontos em que Hildegarda é declaradamente conservadora é em relação a não ordenação sacerdotal de mulheres na Igreja, entendendo que, na grande interação holística do cosmo, na qual o micro deve estar em sintonia com o macro, "as mulheres estavam designadas a ter filhos e criá-los" (HILDEGARDA de Bingen. Scivias, II, 6, 2013), de forma que o sacerdócio era uma atividade incompatível com a função biológica. Por isso Santa Hildegarda dava capital importância ao casamento, o que a tornava fiel e querida pela ortodoxia católica, conforme comenta Maria Carmen Poll:

A pronta aceitação de Hildegarda no meio eclesiástico não se deve a um único fator, mas um motivo se destaca: a clara ortodoxia de Hildegarda. Não há dúvida que os prelados se sentiram em grande parte atraídos por essa ortodoxia: no Scivias, Hildegarda enfatiza doutrinas como a origem divina do casamento, a santidade da eucaristia e a 
dignidade do sacerdócio, que os Cátaros negavam veementemente $(2010$, p. 660$)$.

Portanto, como ressalta Diana Arauz Macedo, destacando-se em relação a outras pensadoras medievais, que de alguma forma aceitaram a sua condião social,

para esta inigualável escritora não foi suficiente rebater as acusações proferidas contra o gênero feminino, senão que também contribuiu para corrigir a tradição pejorativa formada historicamente contra elas; as mulheres - independentemente de sua condição - necessitavam educar-se desde cedo fora dos âmbitos dos âmbitos privados, pois estavam capacitadas igualmente aos homens para receber, produzir e transmitir sabedoria, razão pela qual a autora se encarregou de valorizar as contribuições femininas no campo das técnicas, das ciências e das artes, através de suas personagens. Uma mente tão lúcida que propõe soluções para crise política e religiosa de sua época e que, por sua vez, levantava os direitos das mulheres baixomedievais como parte integrante dessa cotidianidade, não teria aceitação em uma sociedade que tradicionalmente vinha marcando os espaços determinados a cada gênero, e o das mulheres correspondia de forma exclusiva ao âmbito privado, ao lado de seus familiares, ou recolhidas em oração. Apesar disto, o discurso das composições poéticas, das obras alegóricas, políticas e éticas desta grande erudita retomariam dentro das novas concepções do século XVI, dando lugar ao movimento conhecido como a «querela das mulheres», e influenciando, por sua vez, na execução de algumas obras concretas como seria o caso do Heptamerón de Margarita de

Ágora Filosófica, Recife, v. 21, n. 2, p. 05-27, mai./ago., $2021 \cdot 23$ 
Navarra (1492-1549) (ARAUZ MACEDO, 2005, p. 219-220).

\section{Referências}

ALBERTO Magno, Pseudo. El De Secretis Mulierum, atribuído a Alberto Magno: estúdio, ediccíon crítica y traduccion de José Pablo Barragán Nieto. Porto: Facukdade de Letras/Gabinete de Filosofia Medieval, 2011. $587 \mathrm{p}$.

ARAUZ MACEDO, Diana. Imagen y palabra a través de las mujeres medievales (siglos IX-XV). Primera parte: Mujeres medievales del Occidente europeo. Escritura e Imagen, v. 1, p. 199-220, 2005.

BARBOSA, Pedro Gomes. A mulher e o sagrado. In: A mulher na história - Actas dos Colóquios Temáticos sobre a Mulher (1999-2000). Moita: Câmara Municipal da Moita, 2001. p. 181-187.

CHRISTINE de Pizan. A cidade das damas. Tradução e apresentação de Luciana Eleonora de Freitas Calado Deplagne. Florianópolis: Editora Mulheres, 2012.

DEPLAGNE, Luciana Eleonora de Freitas Calado. A cidade das damas: a construção da memória feminina no imaginário utópico de Christine de Pizan. Estudo e tradução. Recife: UFPE, 2006. 368 f. Tese (Doutorado em Teoria da Literatura).

DEPLAGNE, Luciana Eleonora de Freitas Calado. Saboreando o saber: a aventura intelectual de Christine de Pizan no seu "Caminho de Longo Estudo". Disponível em: http://www.uesc.br/seminariomulher/anais/pdf. Acesso em: 05.08.2020.

FLORÉZ, Mercedes Arriaga. Poetas italianas de los siglos 
XIII y XIV. In: FLORÉZ, Mercedes Arriaga; CERRATO, Daniele; ADALES, María Rosal. Poetas italianas de los siglos XIII y XIV en La Querella de las Mujeres. Sevilla: ArCiBel Editores, 2012, p. 13-83.

FONSECA, Pedro Carlos Louzada. Christine de Pizan e Le Livre de la Cité des Dames: pontos de releitura da memória misógina da visão tradicional da mulher. In: Anais do V Seminário Internacional Mulher e Literatura [s.d.].

FONSECA, Pedro Carlos Louzada. Christine de Pizan e a releitura da misoginia medieval de Le Livre de la Cité des Dames (O Livro da Cidade das Damas). In: BOVO, Claudia Regina ; RUST, Leandro Duarte ; CRUZ, Marcus Silva da (orgs.). Anais Eletronicos do IX Encontro Internacional de Estudos Medievais: o oficio do Medievalista. Cuiaba: ABREM, 2011. p. 555-561.

KARAWEJCZYK, Mônica. Indivíduo na Idade Média? um estudo de caso: $O$ Espelho de Cristina de Christine de Pisan. História, Imagens e Memórias. n. 4, ano 2, p. 148-164, 2007.

KLAPISCH-ZUBER, Christiane (dir.). História das mulheres (2): a Idade Média. Trad. de Ana Losa Ramalho et al. Porto: Edições Afrontamento; São Paulo: EBRADIL, 1990. v. 2, 623 p.

LEITE, Lucimara. Christine de Pizan: uma resistência na aprendizagem da moral da resignação. São Paulo: USP, 2008. 223 f. Tese (Doutorado em Língua e Literatura Francesa e Estudos Medievais).

LEITE, Lucimara. Pontos em comuns entre os textos de Christine de Pizan La Cité des Dames, Les Trois Vertus e Le Messager de Paris. Revista Signum - ABREM. Cuiabá, n. v. 2, n. 2, p. 163-187, 2011. 
LEMARCHAND, Marie-José. Introducción. CHRISTINE de Pizan. La Ciudad de las Damas. Introducción, traducción, notas y bibliografia de Marie-José Lemarchand. Madrid: Ediciones Sirueta, 2000, p. 11-56.

LIMA, Vilma Gomes de. $\mathbf{O}$ desafio de ser letrada na Idade Média: uma leitura de Christine de Pizan. Maringá: Universidade Estadual de Maringá, 2011. 23 f. Monografia (Curso de Pedagogia).

MUNIZ, M. R. C. O leal conselheiro de Dom Duarte e a tradição dos Espelhos de príncipe. São Paulo: USP, 2003. Tese (Doutorado em Literatura Portuguesa).

NERI, Christiane Soares Carneiro. Feminismo na Idade Média: conhecendo A Cidade das Damas. Revista Gênero \& Direito. v. 1, p. 68-85, 2013.

POLL, Maria Carmen Gomes Martiniano de Oliveira van de. A espiritualidade de Hildegarda von Bingen; profecia e ortodoxia. São Paulo: USP, 2010. 211 f. Tese (Doutorado em História Social).

RÉGNIER-BOHLER, Danielle. Vozes literárias, vozes místicas. In: DUBY, George; PERROT, Michelle (orgs.). KLAPISCH-ZUBER, Christiane (dir.). História das mulheres no Ocidente (2): a Idade Média. Trad. de Ana Losa Ramalho et al. Porto: Edições Afrontamento; São Paulo: EBRADIL, 1990. v. 2, p. 517-591.

SARANYANA, Josep-Ignasi. História de la filosofia medieval. 3. ed. Pamplona: EUNSA, 1999.

SARANYANA, Josep-Ignasi. La noción de 'liberdad' en el contexto de la mística neoplatónica - a propósito del Speculum animarum simplicium de Margarita Porete (+1310). In: STEIN, Ernildo (org.). A cidade dos homens e a 
Cidade de Deus. Festschrift para Luis Alberto de Boni. Porto Alegre: EST, 2007, p. 106-114.

SCHMIDT, Ana Rieger. Christine de Pizan contra os filósofos. In: SCHMIDT, A. R.; SECCO, G. D.; ZANUZZI, I. (orgs.). Vozes femininas na filosofia. Porto Alegre: Editora da UFRGS, 2018. p. 15-35.

SOUZA, Daniele Shorne de. 0 conhecimento não corrompe: o pensamento utópico de Cristina de Pizán no alvorecer da modernidade. Curitiba: PUCPR, 2008, $67 \mathrm{f}$. Monografia (Graduação em História).

SOUZA, Daniele Shorne de. A cidade das damas e seu tesouro: o ideal de feminilidade para Cristina de Pizan na França no início do século XV. Curitiba: PUCPR, 2013, 142 f. Dissertação (Mestrado em História).

WÜNSCH, Ana Miriam. O que Christine de Pizan nos faz pensar. In: Anais do II Seminários de Estudos Medievais da Paraíba. 13 de junho de 2012.

Marcos Roberto Nunus Costa

Doutorado em Filosofia pela PUCRS, Pós-doutorado em Filosofia pela Universidade do Porto, professor efetivo do Departamento de Filosofia da UFPE.

E-mail: marcosnunescosta@hotmail.com

\section{Rafael Ferreira Costa}

Graduado (Licenciatura e Bacharelado) em História, pela UFPE, Mestre em História da Arte, pela Universidade do Porto - Portugal, e doutorando em História pela Universidade Federal de Pelotas-RS.

E-mail: rafael.fe.costa@gmail.com

Submetido: 22/08/2021

Aprovado: 15/19/2021

Ágora Filosófica, Recife, v. 21, n. 2, p. 05-27, mai./ago., $2021 \cdot 27$ 